\author{
I. Paciência ${ }^{1,2}$, J. Cavaleiro Rufo ${ }^{1,2}$, A. I. Ribeiro ${ }^{1,3}$, F. C. Mendes ${ }^{1,2}$, M. Farraia ${ }^{1,2}$, \\ D. Silva' 2 L. Delgado ${ }^{2}$, A. Moreira ${ }^{1,2,4}$
}

\title{
Association between the density and type of trees around urban schools and exhaled nitric oxide levels in schoolchildren
}

\author{
${ }^{1}$ EPIUnit, Institute of Public Health, University of Porto, Porto, Portugal \\ ${ }^{2}$ Service of Basic and Clinic Immunology, Departament of Pathology, School of Medicine, University of Porto, \\ Porto, Portugal \\ ${ }^{3}$ Department of Public Health and Forensic Sciences and Medical Education, School of Medicine, University of Porto, \\ Porto, Portugal \\ ${ }^{4}$ Faculty of Nutrition and Food Science, University of Porto, Porto, Portugal
}

\section{KEY WORDS}

Children; exhaled nitric oxide; greenness; school neighborhood; tree density; environment.

\section{Corresponding author}

Inês Paciência

Service of Basic and Clinical Immunology

Department of Pathology

School of Medicine

University of Porto

Alameda Prof. Hernâni Monteiro

4200-319 Porto, Portugal

E-mail: inespaciencia@gmail.com

Doi

10.23822/EurAnnACI.1764-1489.162

\begin{abstract}
Summary
Greenspaces in school's neighbourhood represent an important environment to promote healthy development. The aim of this study was to assess the association between the density and type of trees around schools and exhaled Nitric Oxide (NO) levels in schoolchildren. Data on 845 children from 20 primary schools in Porto was analysed. Airway inflammation was assessed by measuring exhaled NO level. The density and type of trees were quantified within a 500 $m$ buffer around schools. Associations were estimated using mixed-effect models. A significant association was observed between non-tree covered areas around schools and exhaled NO levels in schoolchildren ( $\beta=-1.42,95 \% C I-2.84,-0.001)$. Our results suggested that the presence of trees in school neighbourhoods may play a role in the biological mechanisms underlying the complex links between environment and airway inflammation.
\end{abstract}

\section{Introduction}

Growing urbanization is globally changing urban-natural environment, biodiversity as well as human lifestyles, which may have important public health implications $(1,2)$. Although urban life offers a greater access to community services, it is also associated with increased exposure to air pollution and loss of natural environments $(3,4)$. With hasty global urbanization, there is an increasing interest in understanding how urban settings and environment affect children's health.
Urban green spaces not only provide balance for ecosystems but can also act as a buffer against exposure to air pollution, by removing pollutants from the atmosphere $(18,19)$. Pollutants may be removed from the atmosphere through wet and dry deposition on the tree surface and/or by stomatal adsorption and absorption processes (20). Knowledge on how greenspaces affect human health is crucial in addressing the increasing prevalence of asthma and allergies worldwide and to direct urban and community planning for a healthy environment $(21,22)$. Previous studies have examined the effect of air pollution ex- 
posure on exhaled Nitric Oxide (NO) levels, as a non-invasive measure of airway inflammation (23), but no studies evaluate the role of greenspaces on exhaled NO in children. Thus, the aim of this study was to assess the association between the density and type of trees around schools and exhaled NO levels in schoolchildren.

\section{Materials and methods}

The present study included participants from a cross-sectional study assembled in 20 primary schools in Porto, Portugal, corresponding to a total of 71 assessed classrooms (24). The University Health Ethics Committee approved the study, and informed consent was obtained from the children's legal guardians. All research was performed in accordance with the Declaration of Helsinki.

\section{Physical and clinical assessment}

A self-administered ISAAC-based questionnaire (25) was filled out by children's parents covering information on social, demographic and behavioural characteristics and questions regarding the respiratory/allergic health of the children. A physical and clinical assessment, including height, weight, spirometry with bronchodilation, exhaled NO, and Skin-Prick-Tests (SPTs) were performed by trained health professionals (24).

Lung function and airway reversibility were assessed by spirometry according to ATS/ERS guidelines (26) using a portable spirometer (MIR Spiro bank, A23-04003237) before and $15 \mathrm{~min}$ utes after the inhalation of $400 \mu \mathrm{g}$ of salbutamol. The definition of asthma was based on clinical and functional criteria: self-report of asthma diagnosed by a physician (medical diagnosis), with reported asthma symptoms over the past 12 months and/ or at least a $12 \%$ and over $200 \mathrm{~mL}$ increase in FEV1 (Forced Expiratory Volume in 1 second) after bronchodilation (27).

Airway inflammation was assessed by measuring the fractional exhaled NO level using a NO breath analyzer (Bedfont Scientific, Ltd.) in accordance with the ATS guidelines (28).

SPTs were performed on children forearm using a QuickTest ${ }^{\mathrm{TM}}$ applicator (Hall Allergy) and allergen extracts of house dust mite, mix of weeds, mix of grasses, cat dander, dog dander and Alternaria alternata, a negative (extracts diluent) and a positive control (histamine at $10 \mathrm{mg} / \mathrm{mL}$ ) (Hall Allergy, Netherlands). Results were read 20 minutes afterwards and atopy was defined by a positive SPT to at least one of the allergens.

\section{Density and type of trees}

Dominant leaf type (broadleaved/coniferous) and tree cover density (percentage of tree coverage, 0 to $100 \%$ ) at $20 \mathrm{~m}$ spatial resolution were obtained from the 2015 High Resolution Layer
(HRL) Forest products, which can be obtained from the Copernicus Land Monitoring Service (CLMS), coordinated by the European Environment Agency (EEA) (29).

A circular buffer of 500 metres around each participant's primary school address was created (figures 1, 2) in ArcGIS 10.5.1 (Environmental Systems Research Institute, ESRI, Redlands, CA, USA). This buffer has been previously considered by Paciência et al. (9) since it is considered a reasonable walking distance for children as described by Brownson et al. (30).

Then, each buffer was overlaid with the maps depicting the dominant leaf type and tree cover density to determine the tree cover density $(0-100 \%)$ and the percentage of area covered by each dominant leaf type in the school surroundings. Overlay operations were performed using QGIS 3.8. Weighted average of tree cover density and the total area of broadleaves, coniferous and non-tree covered area were calculated for each school's neighbourhood to determine the percentage and type of trees.

\section{Study participants}

In total, 1602 children (7-12 years old), all in the $3 \mathrm{rd}$ and/or 4th grades, were invited to participate. Among them, $686 \mathrm{did}$ not return the signed informed consent form (participation rate of $57 \%$ ), and 58 refused to perform clinical tests.

\section{Data analysis}

Distribution of continuous variables was analysed for normality. Whenever non-Gaussian distributions were observed, non-parametric tests were performed for inferential statistics. The Kruskal-Wallis test was used to compare variables between girls and boys. Significant differences were defined according to an $\alpha$-value of $5 \%(p<0.05)$. Mixed-effect models with a random effect at school-level were used to measure the influence of density and type of trees around schools on exhaled NO levels in children. The Intraclass Correlation Coefficient (ICC) was used to quantify the proportion of the total variance that is at the school's neighbourhood level. The following confounders were considered in the adjusted models: age, sex, asthma, atopy, parental education level and exposure to tobacco smoke at home. Associations were expressed as standardized beta coefficients, $\beta$, and 95\% CI. Statistical analysis was performed using R.

\section{Results}

Among the 858 included children, 13 were excluded due to poor quality lung function test data. Hence, this study was based on data from 845 children $(49.2 \%$ girls) (table I). The median $\left(25^{\text {th }}-75^{\text {th }}\right)$ levels of exhaled NO was $11.0(6.0-20.0)$ ppb, being higher among boys (12.0 (6.0-21.0) vs 10.0 (6.0$17.5), \mathrm{p}=0.004)$. The prevalence of asthma, atopy and rhinitis 
Figure 1 - Percentage of tree cover around each primary school. Each school was represented by a point and a circular buffer of 500 metres.

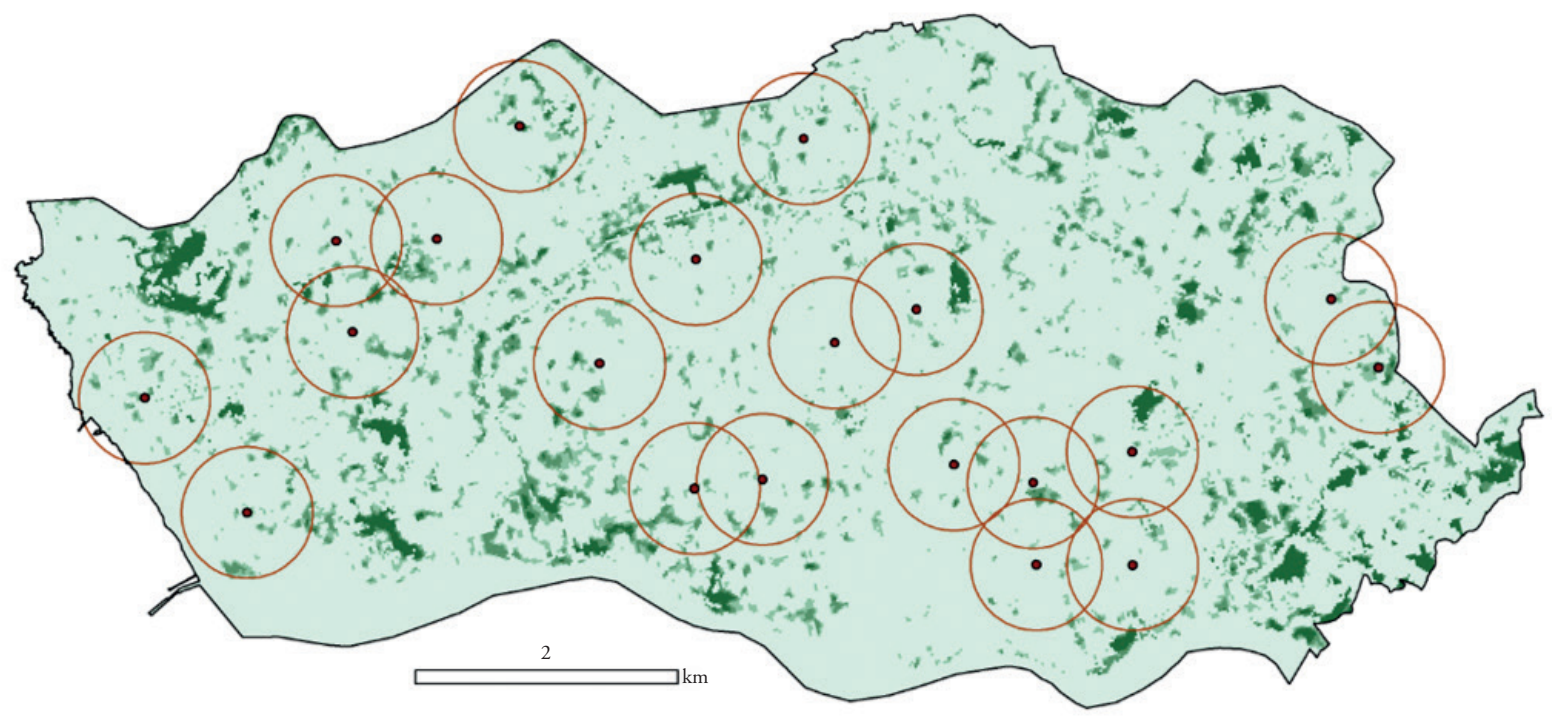

Tree coverage (\%)

$60-100 \quad$ school location

Figure 2 - Dominant leaf type around each primary school. Each school was represented by a point and a circular buffer of 500 metres.

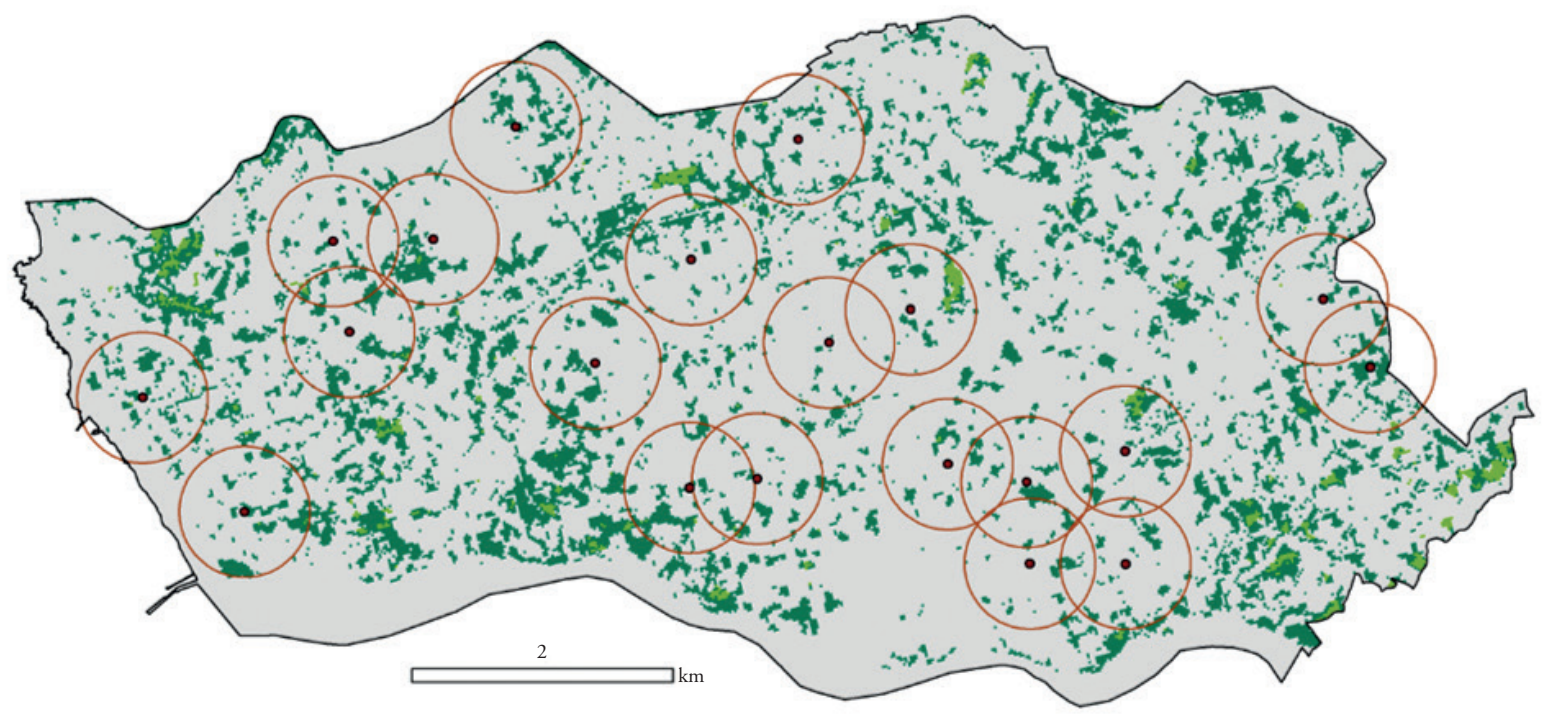

Dominant leaf type

broadleaved trees

coniferous trees

- school location 
was $9.5 \%, 35.4 \%$, and $13.4 \%$, respectively. The prevalence of overweight or obesity was nearly $30 \%$ (table I).

The surrounding density and type of trees is presented in table II. The percentage of tree cover ranged from $16 \%$ to $37 \%$, and the median area covered by coniferous and broadleaves was 10.8 ha and 0.12 ha, respectively. The median $\left(25^{\text {th }}-75^{\text {th }}\right.$ percentile) of non-tree covered area was 64.6 ha (58.5-66.7 ha) (table II). Positive Pearson's correlations were found between tree cover density and type of trees (rho $=0.430$ (broadleaves) and 0.751 (coniferous), $\mathrm{p}<0.05)$. The density of tree cover and the distribution of broadleaves and coniferous was significantly different between schools $(\mathrm{p}<0.05)$.

A significant association was found between non-tree covered areas around school and the levels of exhaled NO in schoolchildren (model 2: $\beta=-1.42$, 95\% CI - 2.84, - 0.001). An increment of $10 \mathrm{~m}^{2}$ in non-tree covered areas around schools was associated with a decrease of $1.4 \mathrm{ppb}$ in exhaled nitric oxide levels. The association was similar but non-significant between the presence of broadleaves $(\beta=-0.14,95 \% \mathrm{CI}-0.49,0.22)$, coniferous $(\beta=-1.16,95 \%$ CI $-3.09,0.76)$ and tree cover density $(\beta=-0.01,95 \% \mathrm{CI}-0.04,0.01)$ and exhaled NO levels in children (table III).

The ICC revealed that approximately $4.0 \%$ of the variance in the levels of exhaled NO is at neighborhood-level. The tree cover density, non-tree covered areas, broadleaves and coniferous in school's neighborhoods explained 3.84\%, 9.10\%, - 7.76\% and $-3.82 \%$ of the levels of exhaled NO, respectively.

\section{Discussion}

Our study shown how density and type of trees surrounding primary schools may influence the levels of exhaled NO in children. After adjustment, non-tree covered areas around primary schools were inversely associated with children's exhaled NO, independently of asthma and allergy status, suggesting that the presence of trees in school neighbourhood may affect the levels of exhaled NO in both healthy and susceptible children.

The present study has some limitations. The cross-sectional design does not allow the determination of causal associations and exposure-dose assumptions. Furthermore, we did not address the

Table I - Characteristics of the participants.

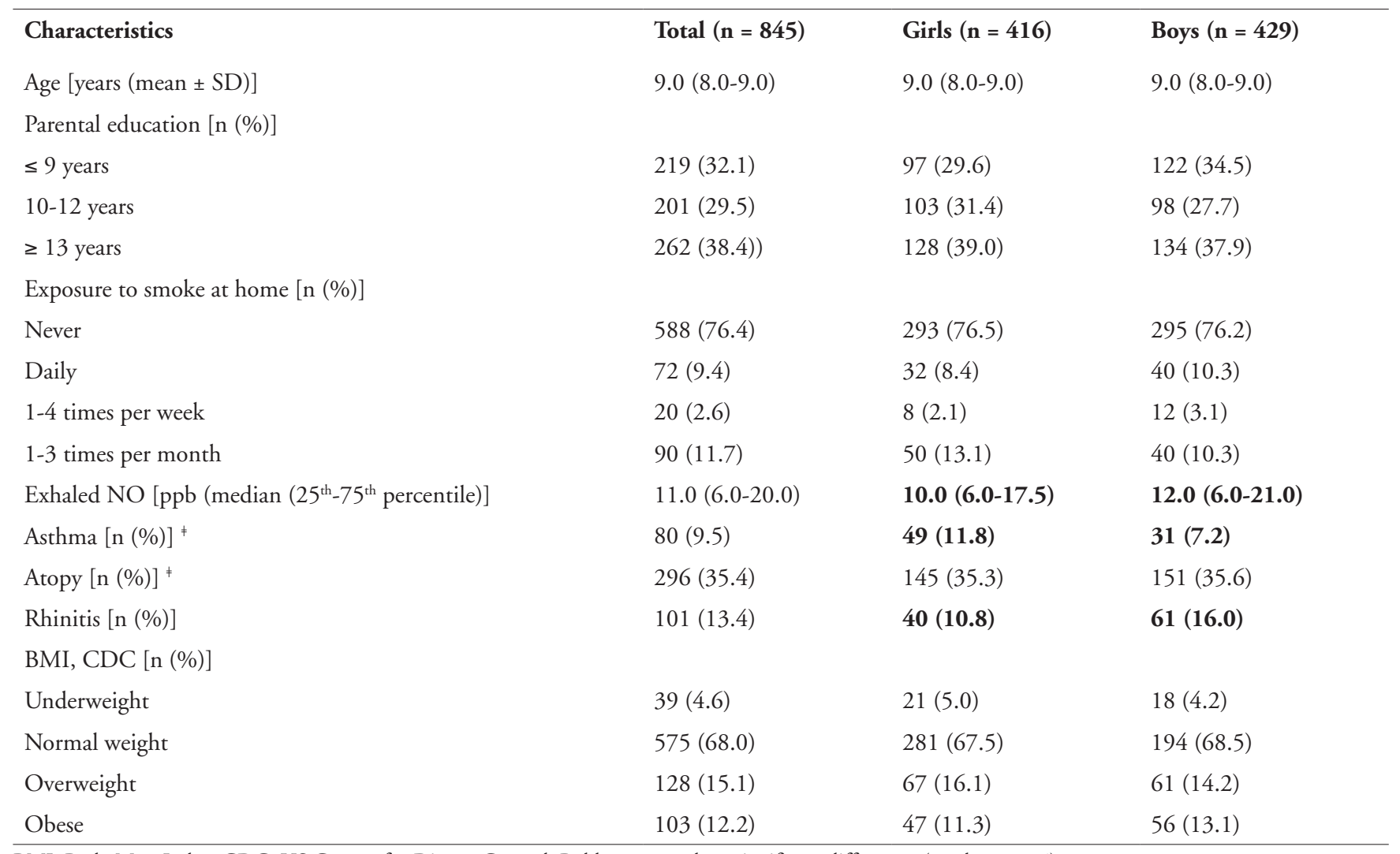

BMI: Body Mass Index; CDC: US Centres for Disease Control; Bold corresponds to significant differences (p value $<0.05$ ). 
quality and type of vegetation or biodiversity. Nevertheless, our analyses were based on the objective measure of tree cover density developed by the European Environmental Agency, allowing a comparison across studies, a better understanding of effects of specific type of trees and the complexities in the interactions between greenspaces and exhaled NO levels, and avoiding bias related to participants' perception of their neighbourhoods. Our results are also limited by low Intraclass Correlation Coefficients (ICCs) generated by the variables of the multilevel analysis. Further, the between-neighbourhood variance was reduced with the inclusion of the individual-level variables of age, sex, asthma, atopy, parental education level and exposure to tobacco smoke at home. However, even low ICCs may have an important impact on levels of exhaled NO in children (31), being important pre-

Table II - Distribution of density and type of trees around schools.

\begin{tabular}{lll}
\hline & Median $\left(\mathbf{2 5}^{\text {th }}-\mathbf{7 5 ^ { \text { th } }}\right.$ percentile) & Min-Max \\
Tree cover density (\%) & $21.0(20.0-27.0)$ & $16.0-37.0$ \\
Non-tree covered area (ha) & $64.5(58.5-66.7)$ & $40.0-69.7$ \\
Broadleaves (ha) & $10.1(7.48-12.2)$ & $2.56-19.3$ \\
Coniferous (ha) & $0.12(0.04-0.48)$ & $0-2.80$ \\
\hline
\end{tabular}

Table III - Multilevel model analysis of the association between density and type of trees and exhaled NO level.

\begin{tabular}{llll}
\hline Characteristics & Total $(\mathbf{n}=\mathbf{8 4 5})$ & Girls $(\mathbf{n}=\mathbf{4 1 6})$ & Boys $(\mathbf{n}=\mathbf{4 2 9})$ \\
Tree cover density & & & \\
$\beta(95 \%$ CI $)$ & --- & $-0.01(-0.02,0.001)$ & $-0.01(-0.04,0.01)$ \\
ICC (\%) & 3.89 & 3.84 & 6.11 \\
Variance & 0.03 & 0.03 & 0.05 \\
Variance explained (\%) & Reference & 1.19 & -45.6 \\
Non-tree covered area & & & \\
$\beta$ (95\% CI) & --- & $-0.89(-2.16,0.38)$ & $-\mathbf{1 . 4 2}(-\mathbf{2 . 8 4 , - 0 . 0 0 1 )}$ \\
ICC (\%) & 3.50 & 3.55 & 4.93 \\
Variance & 0.03 & 0.03 & 0.04 \\
Variance explained (\%) & Reference & 9.10 & -16.0 \\
Broadleaves & & & $-0.14(-0.49,0.22)$ \\
$\beta$ (95\% CI) & --- & $-0.04(-0.20,0.12)$ & 6.78 \\
ICC (\%) & 3.80 & 4.18 & 0.05 \\
Variance & 0.03 & 0.04 & -62.6 \\
Variance explained (\%) & Reference & -7.76 & \\
Coniferous & & & $-1.16(-3.09,0.76)$ \\
$\beta$ (95\% CI) & --- & $-0.51(-1.33,0.32)$ & 6.32 \\
ICC (\%) & 3.60 & 4.03 & 0.05 \\
Variance & 0.03 & 0.03 & -50.9 \\
Variance explained (\%) & Reference & -3.82 & \\
\hline
\end{tabular}

ICC: Intraclass Correlation Coefficient; $\beta$ : beta regression coefficients; 95\% CI: 95\% Confidence Intervals.

Model 0: is null model, baseline model without any exposure variable; Model 1: only included the variable of exposure; Model 2a: adjusted for age, sex, asthma, atopy, parental education level and exposure to tobacco smoke at home. 
dictors of health outcomes and compatible with important policy effects of school's neighbourhood characteristics (32). Finally, other confounders related to exposures at school and home, namely air pollution, was not measured in the study. However, data on asthma, atopy, parental education, and exposure to tobacco smoke were considered as potential confounding factors. The chosen buffer size can also affect the results, however the $500 \mathrm{~m}$ buffer is supported by Browning et al. (33) and Brownson et al. (30), and has been associated with a less prone to exposure misclassification (34).

Our study has also important strengths. To our knowledge, this is the first study evaluating the effect of density and type of trees in schools' neighbourhoods on levels of exhaled NO in schoolchildren. Additionally, we performed a comprehensive clinical assessment with a large number of participants, while controlling for a number of potentially important confounders. The Global Initiative for Asthma (GINA) guidelines define a significant bronchodilator response as an increase in FEV1 $\geq$ $12 \%$, in children (35). However, we considered an increase in FEV $1 \geq 12 \%$ and/or $200 \mathrm{ml}$ as recommended by the NICE guideline committee members (36) as being a more appropriate threshold as evidence of a positive test in response to a standard dose of bronchodilator. In addition, American Thoracic Society recommendations define a significant bronchodilator response as an increase in FEV1 $\geq 12 \%$ and/or $200 \mathrm{ml}$ in both adults and children (37). The effect of trees on schools' neighbourhoods was evaluated using a robust statistical tool that allowed a multilevel approach, considering the complex relationship among the different levels of variables. Nevertheless, it will be important to assess the effect of long-term exposure to school neighbourhoods to understand the extent of health effects.

Nitric oxide is present in exhaled breath and plays a number of key roles in lung physiology, including as a vasodilator, bronchodilator, and inflammatory mediator (38), raising the question of whether exhaled NO can be used as a biomarker of the adverse effect of air pollution on the airways. In addition, Tarantini et al. (39) shown that exposure to air pollutants, including particulate matter $\left(\mathrm{PM}_{2.5}\right)$, may impacts iNOS (induced NOS) promoter methylation. Nitric oxide synthase catalyzes the generation of nitric oxide and three isoforms has been identified - iNOs, eNOS (endothelial NOS) and nNOS (neural NOS). iNOS has been associated to increased levels of nitric oxide, being also responsible for the higher levels of exhaled NO (40). Similar to findings of Tarantini et al. (39), a study including 940 children (6-11 years of age) suggested that the effect of air pollutants on exhaled NO levels may be mediated by a higher iNOS expression due to a lower methylation in iNOS promoter (41). In fact, Salam et al. (41) reported that exposure to higher concentrations of $\mathrm{PM}_{2.5}$ and lower iNOS methylation was related to higher iNOS expression and consequently to higher levels of exhaled NO in children.
Our results suggested that exhaled NO in children may be a sensitive marker for respiratory effects related to school neighborhood. Our results showed that exhaled NO in schoolchildren may decrease with increased percentage of non-tree covered area, tree cover density, broadleaves and coniferous. Green spaces in school neighborhoods can have beneficial effects on air pollution through absorption, providing physical barriers against emission sources, or by limiting the overall area available to sources of pollutants, such traffic or industry $(42,43)$. In fact, in our study the non-tree covered areas were inversely correlated with the presence of fast transit roads and industrial areas surrounding schools, supporting a decrease of pollutants concentration and consequently on the levels of exhaled NO. Mechanistically, a decrease of air pollutants may associate with a lower activation of Transient Receptor Potential channels (TRP), such as TRPA1 and TRPV1, reducing the production of inflammatory cytokines and nitric oxide (44).

Previous studies have also reported associations between exposure to air pollution, especially in children, and increased levels of exhaled NO $(45,46)$. Short-term exposure to higher concentrations of particulate matter $\left(\mathrm{PM}_{2.5}\right.$ and $\left.\mathrm{PM}_{10}\right)$ and ozone were associated with airway inflammation independent of asthma and allergy status (45). The negative impact of exposure to urban environment has also been further reinforced by Berhane et al. (46), in which exposure to urban air, particularly to nitric dioxide and $\mathrm{PM}_{2.5}$, was positively associated with changes in exhaled NO levels in children. The levels of exhaled NO observed in our study were similar to mean values found by Berhane and collegues in 2011 (11.02 ppb in girls and $11.25 \mathrm{ppb}$ in boys) (45) and 2014 (14.8 ppb in girls and $16.6 \mathrm{ppb}$ in boys) (46). Although Berhane et al. (45) underline that levels of air pollution may have the potential to increase the levels of exhaled NO in both healthy and susceptible children, heterogeneity in results may be increased by the different levels of exposure.

Our results suggested that density and type of trees in school neighbourhoods may play a role in the biological mechanisms underlying the complex links between environment and airway inflammation. However, the absolute changes in NO that we observed may be considered small in terms of their possible clinical impact. Additional studies evaluating both the density, type of trees and levels of air pollutants, as well as the interaction with greenspaces and pollution in relation to airway inflammation, should be conducted in order to better understand the mechanisms behind the effects associated with urban environment. Our results suggest that the density and type of trees in school neighbourhood may have an impact on exhaled NO in children. Ultimately, this study supports the concept that urban greenspaces and the presence of trees in school neighbourhoods may be associated with respiratory health in the long-term, contributing to the implementation of future urban planning policies and practices that may promote a healthy lifestyle and reconnection with nature. 


\section{Conflict of interests}

The authors declare that they have no conflict of interests.

\section{Acknowledgments}

Authors gratefully acknowledge the funding by EXALAR 21 project financed by the European Regional Development Fund (FEDER), through the Competitiveness and Internationalization Operational Programme, and by national funding from the Foundation for Science and Technology (FCT) under the scope of the project PTDC/GES-AMB/30193/2017 (POCI-01-0145-FEDER-030193, 02/SAICT/2017 - Project no 30193). This study was also funded by FEDER through the Operational Programme Competitiveness and Internationalization and national funding from the Foundation for Science and Technology - FCT (Portuguese Ministry of Science, Technology and Higher Education) under the Unidade de Investigação em Epidemiologia - Instituto de Saúde Pública da Universidade do Porto (EPIUnit) (POCI-01-0145-FEDER-006862; Ref. UID/DTP/04750/2019). This work was previously presented at the $40^{\text {th }}$ annual meeting of Portuguese Society of Allergology and Clinical Immunology (SPAIC) and published as Abstract in the Journal of the Portuguese Society of Allergology and Clinical Immunology (Rev Port Imunoalergologia 2019;27(suppl 1):5-6).

\section{References}

1. Jowell A, Zhou B, Barry M. The impact of megacities on health: preparing for a resilient future. Lancet Planet Health 2017;1(5):e176-e8.

2. World Health Organization. Urbanization and health. Available from: https:/www.who.int/globalchange/ecosystems/urbanization/en/.

3. McMichael AJ. The urban environment and health in a world of increasing globalization: issues for developing countries. Bull World Health Organ 2000;78(9):1117-26.

4. World Health Organization \& United Nations. Hidden cities: unmasking and overcoming health inequities in urban settings. World Health Organization Centre for Health Development and United Nations Human Settlements Program, 2010.

5. Stigsdotter UK, Ekholm O, Schipperijn J, Toftager M, Kamper-Jørgansen F, Randrup TB. Health promoting outdoor environments associations between green space, and health, health-related quality of life and stress based on a Danish national representative survey. Scand J Public Health 2010;38(4):411-7.

6. Ribeiro AI, Pires A, Carvalho MS, Pina MF. Distance to parks and non-residential destinations influences physical activity of older people, but crime doesn't: a cross-sectional study in a southern European city. BMC Public Health 2015;15(1):593.

7. Wolch JR, Byrne J, Newell JP. Urban green space, public health, and environmental justice: The challenge of making cities 'just green enough'. Landsc Urban Plan 2014;125:234-44.

8. Ribeiro AI, Tavares C, Guttentag A, Barros H. Association between neighbourhood green space and biological markers in school-aged children. Findings from the Generation XXI birth cohort. Environ Int 2019;132:105070.

9. Paciência I, Rufo JC, Silva D, et al. School environment associates with lung function and autonomic nervous system activity in children: a cross-sectional study. Sci Rep 2019;9(1):15156.

10. Ruokolainen L, von Hertzen L, Fyhrquist N, et al. Green areas around homes reduce atopic sensitization in children. Allergy 2015;70(2):195-202.

11. Donovan GH, Gatziolis D, Longley I, Douwes J. Vegetation diversity protects against childhood asthma: results from a large New Zealand birth cohort. Nat Plants 2018;4(6):358-64.

12. Rufo JC, Paciência I, Ribeiro AI. Green Environments and Allergic Diseases in Children: a Scoping Review. Curr Epidemiol Rep 2019;6(4):442-8.

13. Hanski I, von Hertzen L, Fyhrquist N, et al. Environmental biodiversity, human microbiota, and allergy are interrelated. Proc Natl Acad Sci U S A 2012;109(21):8334-9.

14. Fyhrquist N, Ruokolainen L, Suomalainen A, et al. Acinetobacter species in the skin microbiota protect against allergic sensitization and inflammation. J Allergy Clin Immunol 2014;134(6):1301-9. e11.

15. Lehtimaki J, Sinkko H, Hielm-Bjorkman A, et al. Skin microbiota and allergic symptoms associate with exposure to environmental microbes. Proc Natl Acad Sci U S A 2018;115(19):4897-902.

16. Cavaleiro Rufo J, Ribeiro AI, Paciência IR, Delgado JLD, Moreira AMA. The influence of species richness in primary school surroundings on children lung function and allergic disease development. Pediat Allerg Imm 2020;31(4):358-363 .

17. Adamkiewicz G, Ebelt S, Syring M, et al. Association between air pollution exposure and exhaled nitric oxide in an elderly population. Thorax 2004;59(3):204.

18. James P, Kioumourtzoglou MA, Hart JE, Banay RF, Kloog I, Laden F. Interrelationships Between Walkability, Air Pollution, Greenness, and Body Mass Index. Epidemiology 2017;28(6):780-8.

19. Nowak DJ, Crane DE, Stevens JC. Air pollution removal by urban trees and shrubs in the United States. Urban For Urban GreeN 2006;4(3):115-23.

20. Niinemets Ü, Fares S, Harley P, Jardine KJ. Bidirectional exchange of biogenic volatiles with vegetation: emission sources, reactions, breakdown and deposition. Plant Cell Environ 2014;37(8):1790809.

21. Parmes E, Pesce G, Sabel CE, et al. Influence of residential land cover on childhood allergic and respiratory symptoms and diseases: Evidence from 9 European cohorts. Environ Res 2019:108953.

22. Ruokolainen L. Green living environment protects against allergy, or does it? Eur Respir J 2017;49(6):1700481.

23. Kharitonov SA, Yates D, Springall DR, et al. Exhaled nitric oxide is increased in asthma. Chest 1995;107(3):156S-7S.

24. Paciencia I, Cavaleiro Rufo J, et al. Exposure to indoor endocrine disrupting chemicals and childhood asthma and obesity. Allergy 2019;74(7):1277-1291

25. Asher MI, Keil U, Anderson HR, et al. International Study of Asthma and Allergies in Childhood (ISAAC): rationale and methods. Eur Respir J 1995;8(3):483-91.

26. Miller MR, Hankinson J, Brusasco V, et al. Standardisation of spirometry. Eur Respir J 2005;26(2):319-38.

27. Silva D, Severo M, Paciencia I, et al. Setting definitions of childhood asthma in epidemiologic studies. Pediatr Allergy Immunol 2019;30(7):708-715. 
28. Dweik RA, Boggs PB, Erzurum SC, et al. An official ATS clinical practice guideline: interpretation of exhaled nitric oxide levels (FENO) for clinical applications. Am J Respir Crit Care Med 2011;184(5):602-15.

29. European Environment Agency. Copernicus Land Monitoring Service - High Resolution Layer Forest: Product Specifications Document, 2015.

30. Brownson RC, Hoehner CM, Day K, Forsyth A, Sallis JF. Measuring the built environment for physical activity: state of the science. Am J Prev Med 2009;36(4 Suppl):S99-123 e12.

31. Hale DR, Patalay P, Fitzgerald-Yau N, et al. School-level variation in health outcomes in adolescence: analysis of three longitudinal studies in England. Prevention science : the official journal of the Society for Prevention Research 2014;15(4):600-10.

32. Duncan GJ, Raudenbush SW. Assessing the effects of context in studies of child and youth development. Educ Psychol-Us 1999;34(1):29-41.

33. Browning M, Lee K. Within What Distance Does "Greenness" Best Predict Physical Health? A Systematic Review of Articles with GIS Buffer Analyses across the Lifespan. Int J Environ Res Public Health 2017;14(7);675.

34. Fuertes E, Markevych I, Bowatte G, et al. Residential greenness is differentially associated with childhood allergic rhinitis and aeroallergen sensitization in seven birth cohorts. Allergy 2016;71(10):1461-71.

35. Global Initiative for Asthma. 2020 GINA Report, Global Strategy for Asthma Management and Prevention, 2020.

36. National Institute for H, Care E. National Institute for Health and Care Excellence: Clinical Guidelines. Asthma: diagnosis and monitoring of asthma in adults, children and young people. London: National Institute for Health and Care Excellence (UK), 2017. Copyright $^{\odot}$ NICE 2017.
37. Reddel HK, Taylor DR, Bateman ED, et al. An official American Thoracic Society/European Respiratory Society statement: asthma control and exacerbations: standardizing endpoints for clinical asthma trials and clinical practice. Am J Respir Crit Care Med 2009;180(1):59-99.

38. Ricciardolo FLM, Di Stefano A, Sabatini F, Folkerts G. Reactive nitrogen species in the respiratory tract. Eur J Pharmacol 2006;533(1):240-52.

39. Tarantini L, Bonzini M, Apostoli P, et al. Effects of particulate matter on genomic DNA methylation content and iNOS promoter methylation. Environ Health Perspect 2009;117(2):217-22.

40. Rodway GW, Choi J, Hoffman LA, Sethi JM. Exhaled nitric oxide in the diagnosis and management of asthma: clinical implications. Chron Respir Dis 2009;6(1):19-29.

41. Salam MT, Byun H-M, Lurmann F, et al. Genetic and epigenetic variations in inducible nitric oxide synthase promoter, particulate pollution, and exhaled nitric oxide levels in children. J Allergy Clin Immunol 2012;129(1):232-9.e97.

42. van den Bosch M, Nieuwenhuijsen M. No time to lose - Green the cities now. Environ Int 2017;99:343-50.

43. Selmi W, Weber C, Rivière E, Blond N, Mehdi L, Nowak D. Air pollution removal by trees in public green spaces in Strasbourg city, France. Urban For Urban Green 2016;17:192-201.

44. Grace MS, Baxter M, Dubuis E, Birrell MA, Belvisi MG. Transient receptor potential (TRP) channels in the airway: role in airway disease. Br J Pharmacol 2014;171(10):2593-607.

45. Berhane K, Zhang Y, Linn WS, et al. The effect of ambient air pollution on exhaled nitric oxide in the Children's Health Study. Eur Respir J 2011;37(5):1029-36.

46. Berhane K, Zhang Y, Salam MT, et al. Longitudinal effects of air pollution on exhaled nitric oxide: the Children's Health Study. Occup Envir Med 2014;71(7):507-13. 